\title{
The Curious Case of Ice Pellets Over Middle Tennessee on 1 March 2014
}

\author{
MATTHEW R. KUMJIAN \\ Department of Meteorology, The Pennsylvania State University, University Park, Pennsylvania \\ ALEXANDER D. SCHENKMAN \\ Center for the Analysis and Prediction of Storms, University of Oklahoma, Norman, Oklahoma
}

(Manuscript received 21 March 2014; review completed 22 May 2014)

\section{Introduction}

When the surface temperature is $>10^{\circ} \mathrm{C}\left(50^{\circ} \mathrm{F}\right)$ and when the lowest $\sim 2 \mathrm{~km}$ (7000 ft) of the atmosphere is entirely $>0^{\circ} \mathrm{C}\left(32^{\circ} \mathrm{F}\right)$, ice pellets or any other type of winter precipitation type typically are not expected. However, these were the conditions in Middle Tennessee on 1 March 2014 when ice pellets were reported. In fact, the surface temperature at the Nashville International Airport remained $>8^{\circ} \mathrm{C}\left(45^{\circ} \mathrm{F}\right)$ throughout the duration of the ice pellet event.

Public reports of surface-precipitation type and a dual-polarization radar signature provided forecasters with an indication of the rapidly changing conditions after the onset of precipitation. In this note, we examine the unusual conditions that led to ice pellet formation, as well as the added value of crowd-sourced precipitation reports and polarimetric radar observations for operational decision-making in a mixed precipitation event.

\section{Discussion}

The observed sounding at the Nashville National Weather Service (NWS) forecast office in Old Hickory (KOHX) taken at 0000 UTC 1 March 2014 (Fig. 1a) reveals temperatures $>0^{\circ} \mathrm{C}\left(32^{\circ} \mathrm{F}\right)$ throughout the first $2.14 \mathrm{~km}(7035 \mathrm{ft})$ AGL, including a surface temperature $>11^{\circ} \mathrm{C}\left(52^{\circ} \mathrm{F}\right)$. The low-level air mass was extremely dry, especially in the $850-700-\mathrm{hPa}$ layer in which the dewpoint temperatures were $<-40^{\circ} \mathrm{C}$ $\left(-40^{\circ} \mathrm{F}\right)$ and wet-bulb temperatures $\left[T_{w}\right.$; computed as in Bohren and Albrecht (1998)] were $<-5^{\circ} \mathrm{C}\left(23^{\circ} \mathrm{F}\right)$. The Rapid Update Cycle (RUC) analysis sounding from 0000 UTC also shows a dry layer at low levels, though a moist bias is present. Based on Hybrid Single Particle Lagrangian Integrated Trajectory model trajectories (ready.arl.noaa.gov/HYSPLIT.php; not shown) the dry air appears to have been transported from western Canada-associated with an arctic frontal passage a few days prior to the event. NWS forecasters anticipated a chance of light rain throughout the evening associated with the passage of a weak upper-level low, though indicated in their area forecast discussion at 2109 UTC that much of it would evaporate initially before the air could "saturate to the point where rain will reach the ground."

As expected, rain falling into the dry air evaporated, cooling the layer toward $T_{w}$, as revealed in the subsequent RUC soundings (Fig. 1b-f). Only once the air temperature dropped sufficiently low (i.e., close to $T_{w}$ ) via evaporation could raindrops refreeze into ice pellets. This changeover of precipitation type owing to evaporative cooling is analogous to the changeover of rain to snow because of cooling by melting (e.g., Bosart and Sanders 1991; Kain et al. 2000). Because ice pellets do not sublimate as readily as rain evaporates ${ }^{1}$, subsequent cooling and moistening of the layer beneath the refreezing zone would be inhibited, keeping the near-surface air comparatively warm and dry. Note that dry air also delays melting of ice particles (e.g., Rasmussen and Heymsfield 1987; Ryzhkov et al. 2013). The combination of these effects allowed the ice pellets to survive their descent to the surface, while the surface temperature did not decrease dramatically

\footnotetext{
1 This is because of the larger latent enthalpy of sublimation compared to vaporization and the larger saturation vapor pressure over water compared to ice at a given temperature.
} 

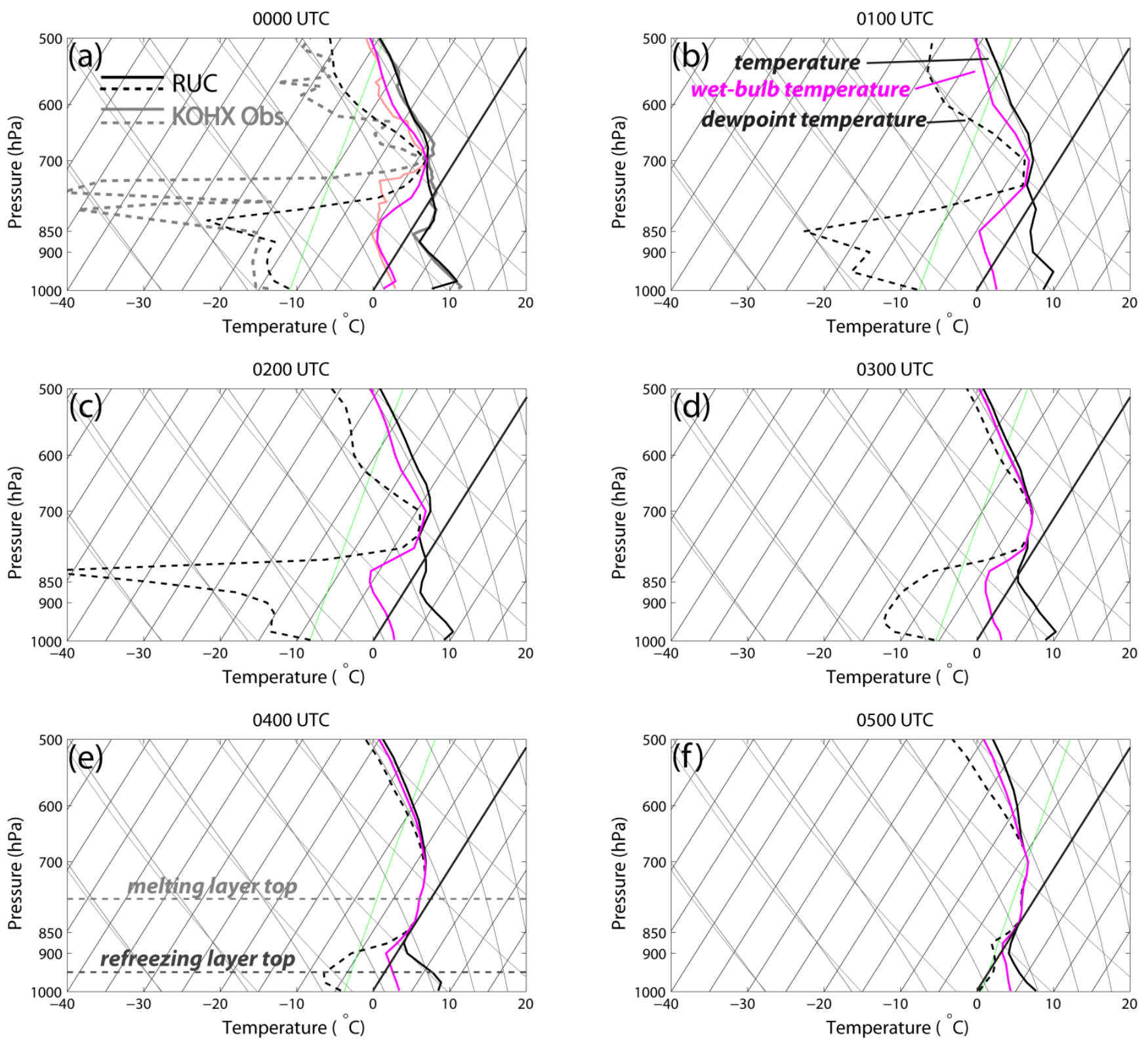

Figure 1. RUC model analyzed temperature (solid black) and dewpoint temperature (dashed black curve) profiles displayed as skew $T-\log p$ diagrams for every hour starting 0000 UTC 1 March 2014. Panel (a) also shows the observed temperature (solid gray) and dewpoint temperature (dashed gray) from the 0000 UTC sounding launched from KOHX on 1 March 2014. In each panel, the purple line shows the calculated wet-bulb temperature profile. In panel (e), the 0351 UTC radar-indicated melting layer top and refreezing layer top are annotated as light gray and dark gray dashed lines, respectively. Click image for an external version; this applies to all figures hereafter.

[by 0400 UTC, the Nashville automated surface observation station still registered a temperature/dewpoint of $\left.8.3 /-0.8^{\circ} \mathrm{C}\left(47 / 27^{\circ} \mathrm{F}\right)\right]$.

Ice pellets (sometimes mixed with rain) at the surface are verified by reports received by the NWS, as well as by citizen scientists participating in the meteorological Phenomenon Identification Near the Ground project (mPING; Elmore et al. 2014). In Fig. 2, the clustering of mPING reports within $50 \mathrm{~km}$ of the
Nashville radar (KOHX) was observed between 0220 and 0418 UTC (820 to 1018 pm local time). The proliferation of smartphones and web-enabled GPS devices has facilitated such crowdsourcing of meteorological observations, including surface precipitation type (Elmore et al. 2014), urban temperature (Overeem et al. 2013), and surface pressure (Mass and Madaus 2014). The mPING reports provide a valuable resource for observations of surface precipitation type when 


\section{mPING Reports}

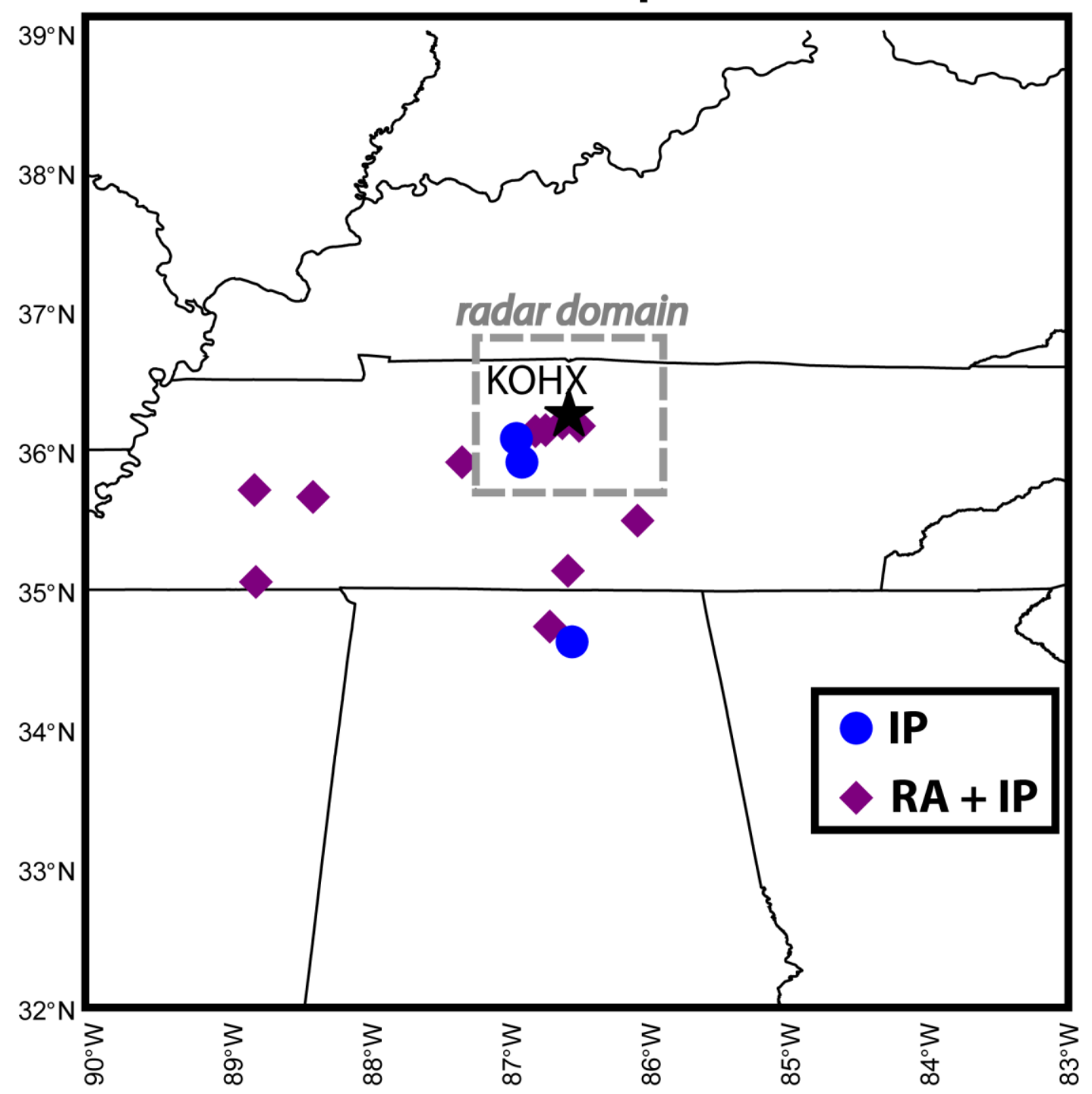

Figure 2. Surface reports of observations of ice pellets (blue circles) or ice pellets mixed with rain (purple diamonds) from mPING on 2330 UTC 28 February 2014 through 0420 UTC 1 March 2014. The location of the radar near Nashville, TN (KOHX), is shown as a black star. An additional personal report from one of the authors (A. Schenkman) is included. The dashed gray box shows the outline of the radar domain displayed in

Fig. 3.

conventional surface reports are unavailable or inadequate.

The complex microphysics leading to ice pellets is reflected in the dual-polarization radar observations taken by $\mathrm{KOHX}$ at higher elevation angles (Fig. 3). The enhancement of differential reflectivity $\left(Z_{\mathrm{DR}}\right)$ and reduction in correlation coefficient [CC; see Kumjian $(2013 \mathrm{a}-\mathrm{c})$ for a description of the polarimetric radar variables] that are particularly evident in the southern and western quadrants at a range between $\sim 35$ and 50 $\mathrm{km}$ is indicative of the melting layer-collocated with an enhancement in reflectivity factor at horizontal polarization $\left(Z_{H}\right)$. Despite the clear radar signature of melting snowflakes, the 0400 UTC RUC sounding shows that temperatures were $<0^{\circ} \mathrm{C}$ at this height (Fig. 1e), indicating a cold bias. Much closer to the radar, at an altitude below the melting layer bright band, is a secondary "ring" of enhanced $Z_{\mathrm{DR}}$ values collocated with reduced CC. This is the refreezing signature first documented by Kumjian et al. (2013). Note that the signature occurs at the driest part of the RUC sounding (Fig. 1e), consistent with the physical interpretation 

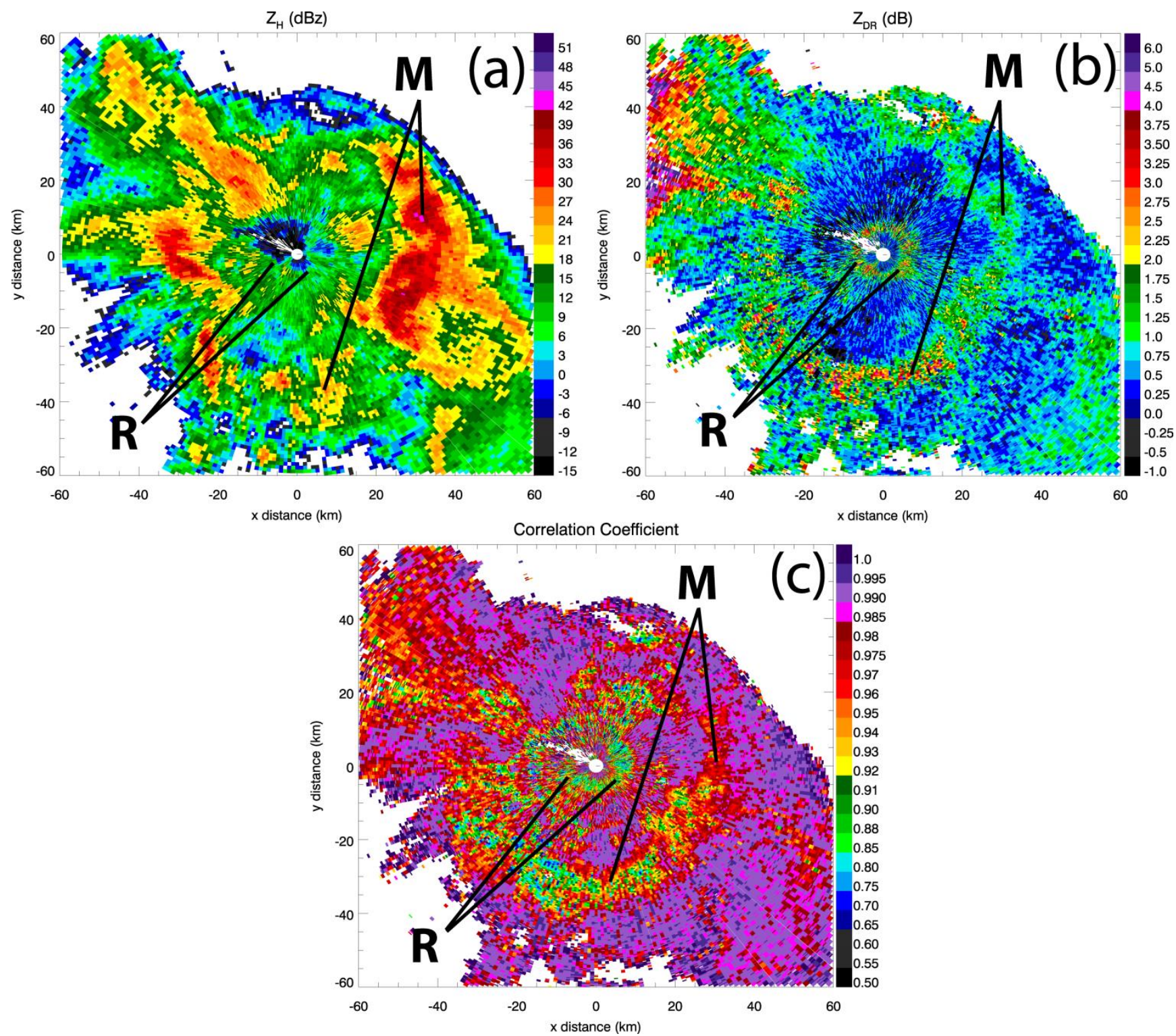

Figure 3. Low-level scan of (a) $Z_{H}$, (b) $Z_{\mathrm{DR}}$, and (c) CC collected with $\mathrm{KOHX}$ at 0351 UTC 1 March 2014 at $3.43^{\circ}$ elevation. The rings of enhanced $Z_{H}$ and $Z_{\mathrm{DR}}$ and reduced $\mathrm{CC}$ values at a range of approximately $30 \mathrm{~km}$ is the melting layer bright band (annotated as "M"), whereas the secondary enhancement of $Z_{\mathrm{DR}}$ and reductions of $Z_{H}$ and $\mathrm{CC}$ within $10 \mathrm{~km}$ range of the radar is the refreezing signature (annotated as "R").

presented above. Keeping in mind the moist bias in earlier analyses, it is likely that the low-level air was drier than suggested by the RUC. The appearance of this refreezing radar signature with a surface temperature near $10^{\circ} \mathrm{C}\left(50^{\circ} \mathrm{F}\right)$ is rather unexpected, but can serve to alert meteorologists to rapidly changing conditions proximal to the areas of precipitation. This is particularly useful in the absence of surface reports. However, because refreezing occurs very close to the ground $(<1 \mathrm{~km} \mathrm{AGL})$, the refreezing signature is only observable at close ranges and, thus, necessitates precipitation near or over the radar location.

\section{Summary}

An unusual case of ice pellets occurred near Nashville, Tennessee, on 1 March 2014, when surface temperatures exceeded $10^{\circ} \mathrm{C}\left(50^{\circ} \mathrm{F}\right)$. As observed on the 0000 UTC sounding and subsequent RUC analysis soundings, dewpoint depressions were extremely large at low levels, so forecasters expected light rain would first evaporate, delaying the onset of precipitation at the surface. However, evaporation of raindrops led to cooling of the air towards its $T_{w}$, which was well below $0^{\circ} \mathrm{C}\left(32^{\circ} \mathrm{F}\right)$. Subsequent raindrops falling into this 
sufficiently cooled layer then refroze into ice pellets that fell to the surface without significant sublimation or melting.

This case demonstrates the important relationship between precipitation microphysics and the environmental thermodynamics, in which precipitation may locally modify the air mass substantially. Such changes may not be reflected immediately in conventional surface observations. However, mPING and other public reports of ice pellets alerted forecasters to the presence of locally changing conditions. Additionally, the refreezing signature in the polarimetric radar measurements is a manifestation of otherwise unobservable microphysical processes, indicating ice pellet formation aloft in an environment seemingly not conducive to refreezing. Though this particular event was not especially hazardous, it demonstrates how crowdsourced public reports of precipitation type and dualpolarization observations, including the refreezing signature, potentially are important tools for nowcasting in winter storms.

Acknowledgments. The authors thank the Nashville NWS office for fielding a phone call during the event and discussing the case with the first author. Funding for this study comes from NSF grant AGS-1143948. Chad Bahrmann is thanked for his assistance in processing the level-III radar data. mPING reports are courtesy of the National Severe Storms Laboratory in Norman, Oklahoma. We greatly appreciate constructive reviews from Angela Lese (NWS Nashville), Dave Schultz (Univ. of Manchester, UK), and an additional anonymous reviewer.

\section{REFERENCES}

Bohren, C. F., and B. A. Albrecht, 1998: Atmospheric Thermodynamics. Oxford University Press, 402 pp.

Bosart, L. F., and F. Sanders, 1991: An early-season coastal storm: Conceptual success and model failure. Mon. Wea. Rev., 119, 2831-2851, CrossRef.
Elmore, K. L., Z. L. Flamig, V. Lakshmanan, B. T. Kaney, V. Farmer, H. D. Reeves, and L. P. Rothfusz, 2014: mPING: Crowd-sourcing weather reports for research. Bull. Amer. Meteor. Soc., in press, CrossRef.

Kain, J. S., S. M. Goss, and M. E. Baldwin, 2000: The melting effect as a factor in precipitation-type forecasting. Wea. Forecasting, 15, 700-714, CrossRef.

Kumjian, M. R., 2013a: Principles and applications of dualpolarization weather radar. Part I: Description of the polarimetric radar variables. J. Operational Meteor., 1 (19), 226-242, CrossRef.

, 2013b: Principles and applications of dual-polarization weather radar. Part II: Warm- and cold-season applications. J. Operational Meteor., 1 (20), 243-264, CrossRef.

2013c: Principles and applications of dual-polarization weather radar. Part III: Artifacts. J. Operational Meteor., 1 (21), 265-274, CrossRef.

, A. V. Ryzhkov, H. D. Reeves, and T. J. Schuur, 2013: A dual-polarization radar signature of hydrometeor refreezing in winter storms. J. Appl. Meteor. Climatol., 52, 2549-2566, CrossRef.

Mass, C. F., and L. E. Madaus, 2014: Surface pressure observations from smartphones: A potential revolution for high-resolution weather prediction? Bull Amer. Meteor. Soc., in press, CrossRef.

Overeem A., J. C. R. Robinson, H. Leijnse, G. J. Steeneveld, B. K. P. Horn, and R. Uijlenhoet, 2013: Crowdsourcing urban air temperatures from smartphone battery temperatures. Geophys. Res. Lett., 40, 4081-4085, CrossRef.

Rasmussen, R. M., and A. J. Heymsfield, 1987: Melting and shedding of graupel and hail. Part II: Sensitivity study. J. Atmos. Sci., 44, 2764-2782, CrossRef.

Ryzhkov, A. V., M. R. Kumjian, S. M. Ganson, and A. P. Khain, 2013: Polarimetric radar characteristics of melting hail. Part I: Theoretical simulations using spectral microphysical modeling. J. Appl. Meteor. Climatol., 52, 2849-2870, CrossRef. 